\title{
Brachial artery occlusion with transient finger paralysis related to blood pressure measurements
}

\author{
Kazuaki Tange, MD · Hiroyuki Kinoshita, MD, PhD • \\ Yoshio Hatano, MD, PhD
}

Published online: 13 February 2009

(C) Canadian Anesthesiologists' Society 2009

\section{Erratum to: Can J Anesth/J Can Anesth DOI 10.1007/BF03016359}

In the correspondence entitled: "Brachial artery occlusion with transient finger paralysis related to blood pressure measurements" published in the November 2008 issue, Can J Anesth 2008; 55: 793-4, the Figure is distorted. The publisher encloses a revised version of the Figure and apologizes for this error.

The online version of the original article can be found under doi:10.1007/BF03016359.

K. Tange, MD $\cdot$ H. Kinoshita, MD, PhD $(\varangle)$.

Y. Hatano, MD, PhD

Wakayama Medical University, Wakayama, Japan

e-mail: hkinoshi@pd5.so-net.ne.jp

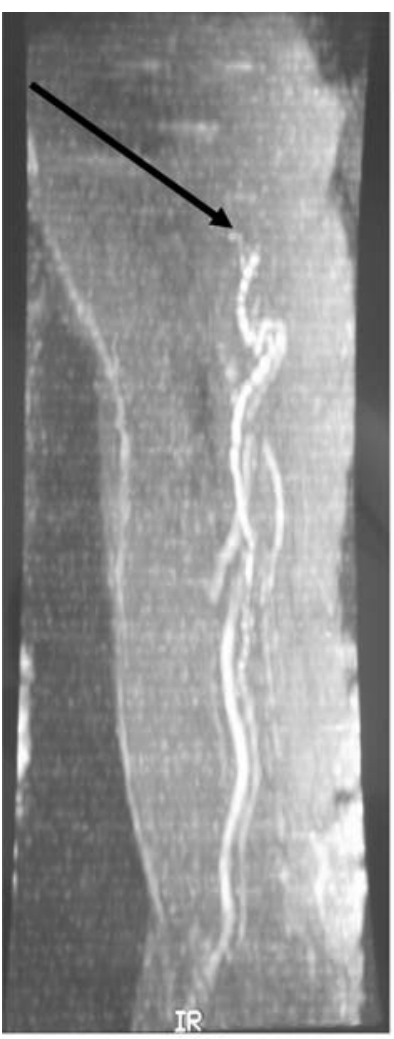

(a) Twenty-four hours after the operation

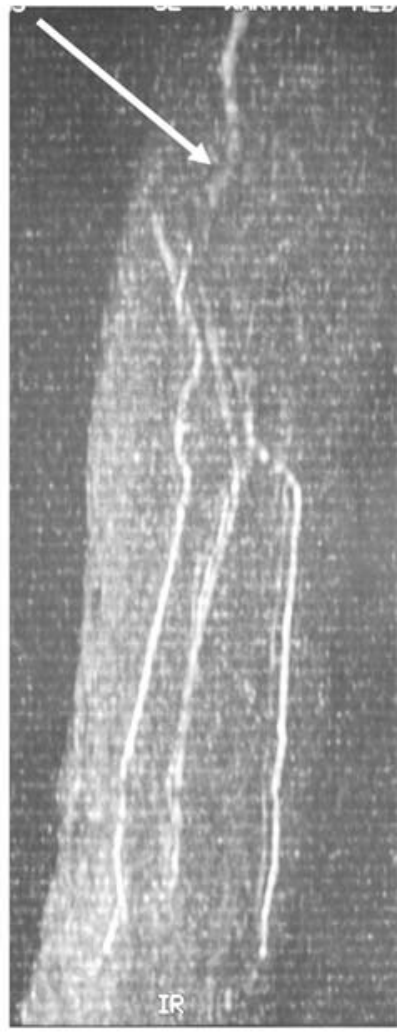

(b) Thirty-six hours after the operation
Figure (Panel A) Twenty-four hr after the operation, magnetic resonance angiography of the patient's right arm documented complete obstruction of the right brachial artery (refer to black arrow [a]), whereas the peripheral arteries appeared to have enough blood flow, probably due to collateral circulation. (Panel B) Thirty-six hr after the operation, the second magnetic resonance angiography revealed re-flow of this artery (refer to white arrow $[\mathrm{b}]$ ) 